\title{
Built environment and car driving distance in a small city context
}

\section{Fitwi Wolday}

Norwegian University of Life Sciences

hamdwold@nmbu.no

\section{Article history:}

Received: March 23, 2017

Received in revised form:

January 23, 2018

Accepted: May 7, 2018

Available online: October 12, 2018

Copyright 2018 Fitwi Wolday

http://dx.doi.org/10.5198/jtlu.2018.1176

ISSN: 1938-7849 | Licensed under the Creative Commons Attribution - Noncommercial License 4.0

The Journal of Transport and Land Use is the official journal of the World Society for Transport and Land Use (WSTLUR) and is published and sponsored by the University of Minnesota Center for Transportation Studies. 


\section{$1 \quad$ Background}

A sizable share of the Norwegian as well as the European ${ }^{1}$ population live in small cities. The latest figures from Statistics Norway, the national statistics office, show that about 23 percent $^{2}$ of the Norwegian population reside in small cities (with inhabitants ranging between 5000 and 30,000). Understanding the dynamics of travel behavior at this geographic scale is important in setting realistic sustainability oriented transportation and environmental goals and consequently designing appropriate policies to achieve them.

Due to the inherent urban structural differences induced by differences in urban size (small vs large cities) and geographic scale of analysis (local vs regional contexts), findings from larger urban areas may not be transferable to small cities. Yet, with very few exceptions (Næss \& Jensen, 2004) small cities have conspicuously been overlooked in travel studies. Much of what we know about the relationship between built environment and travel behavior comes from larger metropolitan areas.

Various studies (Bhat \& Guo, 2007; Hong, Shen, \& Zhang, 2014; Kwan, 2012; Kwan \& Weber, 2008) show that the geographic scale of analysis plays an important role for the significance and validity of empirical assertions on causality between built environment and travel behavior. Hence, knowledge based on a skewed focus towards larger metropolitan areas may lack external validity and thus offer little practical guidance for small-city planners. This article will complement the existing literature by investigating whether, and in which way, the distribution of residential locations in small cities influences travel behavior. Besides urban form characteristics, the article assesses the effect of demographic and socio-economic characteristics on travel behavior.

Most travel, at least most of the non-ad-hoc, recurring travel, starts from home and ultimately ends at home. Once households decide where to reside, travel scheduling decisions such as where to travel, how often, which route to take and which mode of travel to adopt etc. are made with a constant point of reference in mind, which is their place of residence (Ellegard \& Vilhelmson, 2004). Consequently, understanding how the spatial distribution of dwellings relates to people's travel behavior is an important concern for urban planners. Studies in many cities and urban areas show that residential distance from the city center and the spatial configuration around these residences offer a consistent and strong explanation of the variations in travel behavior above and beyond the issue of residential self-selection (Cao, Mokhtarian, \& Handy, 2009; Cho \& Rodríguez, 2014; Ettema \& Nieuwenhuis, 2017; Næss, 2009; Næss, Strand, Wolday, \& Stefansdottir, 2017; Zegras, 2010).

Longer travel distances, lower non-motorized and transit mode shares, as well as higher car use are all strongly associated with residential distance from city centers. These associations make up the core argument for compact urban development as a gateway for sustainable travel. Attesting to this, planning authorities employ land-use strategies as preferred policy tools in reducing car driving and the overall quantity of travel, promote health-enhancing travel habits as well as to curb urban encroachment on nature and agricultural land. Norwegian national planning guidelines, for example, have among their main goals to reduce land-use-induced transport demand and promote environmentally friendly modes of travel. The guidelines state that land development patterns and provision of transportation facilities should promote compact urban development and environmentally friendly means of conveyance. Central locations should be exhaustively utilized through densification before expansive land development could be considered (Norway's Government, 2014). This legal provision allows at the same time for local adaptability. Understanding travel behavioral responses in cities with differing sizes and regional contexts is therefore an important contribution in devising policies to achieve the intended outcomes.

${ }^{1}$ Eurostat news release, 51/2012, March 30, 2012

${ }^{2}$ Statistics Norway, population in urban settlements, 2015 
The distribution of dwellings in the urban space and the regional urban structure within which it is embedded induces people to adopt certain ways of travel. This again depends on the economic and socio-demographic attributes of the traveler, access to alternative means of transport and individual preferences and attitudes. The availability of destinations, the breadth of alternative means of transport and diversity of facilities may in turn be conditional on the size and density of a given urban area (city). To draw meaningful conclusions from the complex web of interrelationships, understanding the appropriate variables to be measured, the geographic scale of analysis and its regional context is therefore vital (Crane \& Guo, 2012). This article will utilize survey data from three small cities with comparable population sizes but varying urban structures and hierarchical position at a regional scale.

The article is organized under seven sub-themes. The next section outlines the research problem and the derived research questions. Section 3 looks into the theoretical framework in some detail, followed by data description in Section 4. Section 5 focuses on the analytical model. Results and discussion appear in Section 6, followed by concluding remarks at the end.

\section{Problem statement and research questions}

The tendency of built environment characteristics to be triggered as causal factors at varying spatial scales is an important dimension in the nexus between built environment and travel behavior (Bhat \& Guo, 2007; Milakis, Cervero, \& van Wee, 2015). This is partly because size and regional hierarchy of cities have significant behavioral implications on travel decisions. Variation in city size is expected to influence people's travel behavior by varying the size of the concentrations of activities of interest as well as the range of activities present. As such, the size of a given city partly determines how different facilities are related in terms of origins and destinations of travel and the modes people use to access them.

One important representation of how facilities are related from travel behavioral perspective is residential distance from the city center. As mentioned in the previous section, residential location is, presumably, the most frequently investigated facility in travel studies, because it is where daily life is planned, travel scheduled, family life organized and not least it is the origin and ultimate destination of most of daily travel activities. Likewise, the city center, by providing the highest concentration of facilities in the urban space, establishes itself, presumably, as a highly attractive destination. The distance of residences from the city center, by bringing together the two important aspects of travel activity (the origin and destination), becomes an important construct in understanding the effect of built environment on travel behavior.

Residential distance from the city center has been an important and consistently robust representation of the influence of built environment on travel behavior in metropolitan areas (Cao, Næss, \& Wolday, 2017; Ewing \& Cervero, 2010; Næss, 2006, 2011; Næss et al., 2017; Zegras, 2010; Zhou \& Kockelman, 2008). In two meta-analyses comparing built environment elasticities, Reid Ewing and Cervero (2010) and Stevens (2017) found residential distance to downtown to be the variable with the strongest influence (in terms of effect size) on driving distance. Investigating whether the same also holds for smaller cities with varying urban hierarchies will be an important contribution to the transferability of findings across city sizes and hence broader understanding of the built environment-travel behavior relationship.

The primary question this paper tries to address is whether car driving distance vary significantly with variation in residential distance from the city center in a small-city context. This main question is addressed by three follow-up questions. Firstly, how does the relationship between car driving distance and residential distance from the city center manifest itself after accounting for differences in demographics, socio-economic attributes and residential preferences? Questions pertaining to the effect of 
socio-economic and demographic attributes on travel behavior while controlling for residential distance from the city center are also addressed here. Secondly, how does the relationship between car driving distance and neighborhood built environment factors look like after accounting for residential distance from the city center, and differences in socio-economic and demographic attributes? Thirdly, how important are neighborhood and city-scale built environment factors in influencing total driving distance in the context of regional influence?

\section{Theoretical framework}

This section explores characteristics that may influence travel behavior in the context of a small city and the theoretical underpinning for those claims. But first, a brief theoretical argument as to why size matters and hence the focus on small cities is in order.

As put forth in Christaller's central place theory (1966), the establishment of firms in a given location depends on the minimum threshold of potential customers, on the one hand, and the maximum range its customers are willing to travel to acquire the goods and services it provides, on the other. Put differently, population size and its geographic distribution is crucial for the constellation of a variety of facilities at a given location. High density implies a threshold (critical mass) being met within a narrower range, which again means a large concentration of facilities in a small area. Although the significance of density is undisputed, it is, however, not a sufficient condition for a wide-ranging diversity to take root, and that is where size comes in. Some occupations require a large customer base and hence a wide catchment area. In such cases, densification may not contribute much unless the size satisfies the minimum threshold required. Population density can therefore be seen as an enabler - an enabler that creates conditions for destinations of interest (such as shops and other facilities) to establish themselves.

In small cities, the diversity of facilities, and therefore the number of potential destinations, will be limited by the low population size of these cities. For small-city dwellers, the significance of the city center as a major trip generator will also likely depend (in part) on city size. As a result, small-city dwellers may, for a variety of facilities, depend on locations other than those in the city where they reside. In this case, the relevance of the center of a small city can be expected to be weakened somewhat. Whether neighboring, higher-order destinations can be viable alternative options will, however, depend on the position of the small city in question in a regional hierarchy of cities and its proximity to the nearest higher-order city.

An attempt to explain the causal nature of the relationship between urban form and travel behavior is a challenging task, given the diversity of reasons people may have for traveling. The multidimensional nature of urban form characteristics, the moderating effect of individual and household characteristics as well as spatial scale of analysis (Bhat \& Guo, 2007; Boarnet \& Crane, 2001a; Ewing et al., 2014) are other additional factors that add to the complexity. Fortunately, a lot of progress has been made in not only describing but also in explaining travel behavior (and the role of the built environment) over the last two decades. Boarnet and Crane (2001b), Handy, Cao, and Mokhtarian (2005), Næss (2006, 2013), Røe (2000) and Næss (2015) are a few among several influential studies that have documented the theoretical grounds as to how and why built environment has causal influence on travel behavior.

On the empirical front, residential distance from the city center has been found to exert a consistent positive influence on the extent of car use (Næss, 2011; Zegras, 2010; Zhang, Hong, Nasri, \& Shen, 2012) while high local density has been found to promote non-motorized travel. Jobs located at highdensity destinations generate a large proportion of commutes by transit (Næss, 2012). Similarly, Cervero and Kockelman (1997) found that mixed development, density and pro-walking design elements discourage car use and promote non-motorized travel. Still, the influence of density on travel behavior is to some degree conditional on size of the area studied (Næss, 2011; Zhang et al., 2012). 
Progress in behavioral and empirical modeling in travel research during the last decades has shed light and amended issues that were major sources of inconsistencies in many empirical studies. Two of the most prominent sources of inconsistency across studies are issues related to geographic scale and residential self-selection. The problem related to geographic scale is primarily an empirical problem and has two sources. The first relates to the aggregation of geographic data and is known as the modifiable areal unit problem (MAUP). Aggregation of spatial data can often make empirical results sensitive to the way spatial boundaries or zones are defined (as the basis for aggregation) resulting in inconsistent parameter estimates (Hong et al., 2014).

The second scale-related problem is associated with the spatial uncertainty about the actual geographic areas that exert causal influences (Kwan, 2012). This is distinct from MAUP and is known as uncertain geographic context problem (UGCoP). Arbitrarily delimiting a certain location in a continuous urban settlement and analyzing it independent of the wider urban context it is part of, presents certain challenges. Neighborhood-scale studies usually give a higher relative weight to built environment factors around residence and less attention to relevant attributes associated with important destinations further away from place of residence such as work commutes (Crane \& Guo, 2012). Considering that individuals in contemporary high-mobility and specialized societies tend to choose among facilities within a wider acceptable travel distance rather than choosing the closest single facility of a category (Næss, 2011, 2013) , neglecting geographic scale related issues could lead to serious inconsistencies in research findings.

The availability of agent-based disaggregate data with high geographic resolution solves empirical challenges associated with MAUP (Fotheringham, 1989). Likewise, UGCoP is mainly addressed by adopting empirical models where neighborhood as well as city-scale variables are integrated in to the same analysis. Considering accessible destinations by mode as well as city-scale variables such as residential distance from the city center has the potential to avoid biases resulting from not including a significant part of the agent's activity space. This paper employs disaggregate neighborhood and city-scale variables. Population density is measured for $250 \mathrm{mx} 250 \mathrm{~m}$ grid cells containing the residence. Moreover, residential distance from the city center is measured along the road network for each residential unit (respondent) using Arc Map.

The second problem that has been the subject of intense debate during the last decade is residential Self-selection (RSS). The discussion on the magnitude of causal influence between built environment and travel behavior has been revolving around the issue of RSS. RSS refers to the assumption that individuals choose their residential location based on their travel preferences. A strong tendency for RSS means that travel attitude confounds the relationship between built environment and travel behavior and therefore has to be controlled for in empirical analyses, as do many studies (Cao \& Cao, 2014; Circella, Mokhtarian, \& Handy, 2008; Frank, Saelens, Powell, \& Chapman, 2007; Handy, Cao, \& Mokhtarian, 2006; Kitamura, Mokhtarian, \& Laidet, 1997). The working assumption in controlling for RSS has been that the effect of built environment on travel behavior will be biased upwards if RSS is not accounted for.

However, recent theoretical and empirical studies indicate that controlling for RSS can also lead to underestimation of the true built environment effects (Cao \& Chatman, 2016; Chatman, 2009, 2014; Næss, 2009). Furthermore, some recent studies question the magnitude and significance of the influence of travel attitudes on residential location decisions. Næss (2009, 2014), for example, presents empirical as well as theoretical grounds showing that RSS does not significantly bias the effect of built environment on travel behavior. Ettema and Nieuwenhuis (2017), on their part, found RSS and built environment to be marginally confounding as strong travel preferences translate only weakly into residential selection. Also, studies that looked into the relative priority of various factors in residential loca- 
tion choice found travel preference to be second-tier as a selection criteria in residential location choice (Cao, 2008; Filion, Bunting, \& Warriner, 1999; Wolday, Cao, \& Næss, 2018).

A sound theory is antecedent to sound empirical models (Kendall \& Stuart, 1961). Although controlling for RSS has been standard practice in land-use and travel behavior studies during the last couple of decades, this paper assumes the role of RSS in discounting the influence of built environment on car driving distance in the context of a small city to be marginal at best. Because of the smaller geographic size, the average distance to facilities within the small-city limits is relatively short and the diversity of transit services or hindrances to car use is limited. Nonetheless, residential preferences may represent individual heterogeneities that are correlated with built environment characteristics, which can have implications for car driving distance (confounding effect). Therefore, this paper will address whatever little effect self-selection might have, by explicitly specifying residential preferences in its analytical model and thereby empirically sorting out potential confounding effects.

Despite the immense research focus on the built environment-travel behavior relationship and advances in modeling it during the last decade, external validity considerations seem to have received limited attention. To my knowledge, the few studies that set out to address external validity such as Ewing et al. (2014) limit themselves to harmonizing types of built environment variables and the measurement methods employed. Differences in city size across study areas and how that influences the relationship between built environment and travel behavior are rarely addressed. ${ }^{3}$ The few studies (Sun, He, Zhang, \& Wang, 2016; Zhang et al., 2012) that have addressed this, show that the effectiveness of many built environment attributes in reducing driving distance is conditional on city size.

This study intends to fill the void in the literature by employing disaggregate data obtained from three Norwegian small cities and considering the local as well as the regional structural contexts in which the cities are embedded.

\section{Data description}

The scope of the study is limited to small cities with populations in their continuous built-up area ranging between 10000 and 20000 inhabitants (Table 1). The data was collected using a web survey from three small cities: Kongsvinger, Jessheim and Drøbak in the municipalities of Kongsvinger, Ullensaker and Frogn, respectively. In larger cities, the continuously built-up area often outstretches the administrative areas and include more than one jurisdiction. In small cities however, the continuous built-up area is often smaller than the administrative zone to which it belongs. The three cities discussed here are administrative centers of their respective municipalities and the built-up areas do not outstretch the municipal borders.

Table 1: Aggregate description of survey areas

\begin{tabular}{lllll}
\hline $\begin{array}{l}\text { Settlement areas } \\
\text { (cities) }\end{array}$ & Number of residents & Area $\left(\mathbf{k m}^{2}\right)$ & $\begin{array}{l}\text { Density (residents/ } \\
\left.\mathbf{k m}^{2}\right)\end{array}$ & $\begin{array}{l}\text { Share of municipal } \\
\text { population }\end{array}$ \\
\hline Drøbak & 13405 & 5.52 & 2428.4 & $86 \%$ \\
Jessheim & 16595 & 6.84 & 2426.2 & $51 \%$ \\
Kongsvinger & 11969 & 7.87 & 1520.8 & $67 \%$ \\
\hline
\end{tabular}

Source: Statistics Norway, population in urban settlements, 2015.

The three cities are comparable in terms of population size. Kongsvinger, on the other hand, stands out with a lower population density.

${ }^{3}$ The study by Ewing et al. (2014) does control for likelihood of intraregional clustering of households using hierarchical linear models but does not analyze further the patterns and potential travel behavioral effects of the clustering. 
Drøbak and Jessheim are located at a comparable distance from Oslo, at respectively 39 and 45 kilometers away from the city center of Oslo along the road network at opposite ends of the Oslo metropolitan area. Both cities are connected to Oslo with well-functioning road networks. The two cities do differ, though, in terms of railway infrastructure linking them to Oslo. Jessheim is integrated into the rail network with scheduled train departures to Oslo every half hour while Drøbak is not integrated into the rail network. Compared to Drøbak and Jessheim, Kongsvinger is located further away from Oslo, at a distance of 96 kilometers along the road network. Kongsvinger is integrated into the rail network and has an hourly scheduled train departure to Oslo.

\subsection{Center structure and regional context of the cities}

The three small cities represent three different urban structural conditions both locally (city center structures) as well as in their role in the urban hierarchy in the wider regional context. Jessheim and Drøbak are closer to Oslo than Kongsvinger and hence more integrated in the Oslo metropolitan labor market.

Built environment variables are classified into three categories depending on the geographic scale considered. One, neighborhood scale refers to built environment attributes within the vicinity of the residence. Neighborhood scale refers here to an area within about a kilometer of a residence. Population density is the only neighborhood variable included in this paper. Population density is calculated for a $250 \mathrm{~m} \times 250 \mathrm{~m}$ grid containing the residence. Two, local scale refers to built environment variables that are within the bounds of the particular small city. Local scale variables in this article primarily include job density (which is calculated for an area within $2 \mathrm{~km}$ of the residence), residential distance from the city center and city center structure (polycentric vs monocentric). The local scale also includes neighborhood-scale variables. Three, regional scale refers to variables reflecting regional spatial interactions as a result of a city's level in the urban hierarchy in a regional context. Centrality and distance to the nearest higher-order city are two regional variables considered in this paper.

The centrality variable is defined using commuter flow patterns (Aguilera \& Mignot, 2004). Commuter flows between the case cities and the adjacent urban areas characterizes the small cities as either regional centers or satellites. Kongsvinger, with its secluded location away from regional influences of other major cities, has a smaller proportion of its resident labor force out-commuting. In 2015, 71\% percent of the resident labor force in Kongsvinger municipality were locally employed whereas the corresponding figures for the municipalities containing Drøbak and Jessheim are about 37 and 49 percent, respectively. ${ }^{4}$ On the basis of commuter flow data and proximity to a higher-order urban area, Kongsvinger is defined as regional center while Drøbak and Jessheim are defined as satellites. Table A2 in the appendix summarizes commuter flow pattern for the sample.

Apart from the regional structural disparities, the three cities also differ in the way the city centers are structured. Drøbak city has two competing centers. The city market (Torget) close to the harbor is traditionally considered as the main city center. The second center, AMFI-Drøbak, is a recent development with shopping centers and other service-rendering facilities at the outskirt of the city. Both centers have a significant number of facilities but the largest shopping facilities are located at AMFI-Drøbak. The two centers are about 3 kilometers apart. Jessheim and Kongsvinger, on the other hand, have monocentric urban structures with most of the commercial and other service facilities concentrated in the city center.

The contrast in center structures is reflected by the distribution of facilities in the three cities as

shown by Figure 1. The vertical axis shows the cumulative accessibility to facilities while the horizontal axis represents residential distance (in kilometer) from the city center.

${ }^{4}$ Statistics Norway, register based employment data, 4th quarter, 2015. 


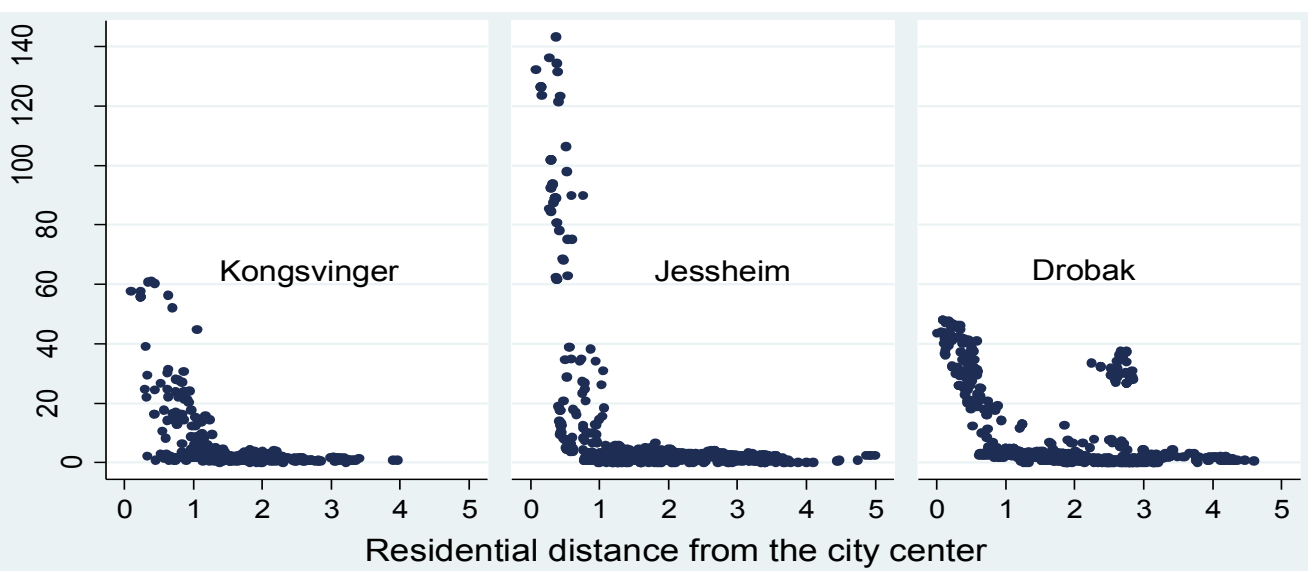

Figure 1: Distribution of accessibility to facilities ${ }^{5}$ in the cityscapes

\subsection{The survey}

The survey was conducted using a self-administered web-questionnaire. The sampling frame was residential units in the continuous built-up area of the three cities. An adult between the age of 18 and 75 was randomly selected from each residential unit resulting in a sample of 4591, 5609 and 5074 potential respondents for Kongsvinger, Jessheim and Drøbak respectively. Response rates for travel surveys nowadays often range between 10 and 20 percent (Hjorthol, Engebretsen, \& Uteng, 2014; Næss, 2016). To mitigate the continuously declining response rates in Norway and elsewhere (Amundsen \& Lie, 2013), I included in my gross sample more than 90 percent of the residential units within the continuous builtup area in each of the three cities.

An invitation letter was sent to each potential respondent in December 2015 with information on the purpose of the survey, how to access and complete the survey and contact information. The survey did not use follow-ups in the form of reminders. ${ }^{6}$ The response rates were $11.1 \%, 11.0 \%$, and $16.6 \%$ for Kongsvinger, Jessheim and Drøbak, respectively. Although the response rates were low, they are within the mainstream and hence typical for surveys administered to the general population. The net sample reflects the population characteristics with minimum skewness, as reported in Table 2 .

Sample demographic characteristics such as household size, average number of children per household, average number of dependents 17 years of age and below, average age of respondents, and gender proportions conform well to their population counterparts in all three cities. On the socio-economic factors, respondents with college education or above seem to be overrepresented. I believe, however, that the disparity is lower than what appears in Table 2 for the following two reasons. The values are calculated slightly differently between the sample and the population. The proportion of respondents with college education in the sample shows the share of college educated individuals in the age bracket of 18 to 75 years. For the municipalities, it is calculated for the population subgroup 16 years or older. Besides, a higher proportion of individuals with college education live in the cities, raising the city average compared to the municipality average. Average household income is also slightly skewed towards higher income individuals, but the difference between the sample and population average is likely to be lower than reported above due to the above two reasons. The employed share of the labor force in the sample mirrors the population average fairly well.

\footnotetext{
${ }^{5}$ Accessibility to facilities is calculated based on gravity model The facilities comprise of grocery stores' medical facilities (medical clinics, dental clinics and pharmacies), restaurants and cafés, facilities for errands other than grocery stores, and fitness centers.

${ }^{6}$ To incentivize participation, respondents who completed the survey were eligible for a gift card lottery worth 6,000 NOK (approx. USD 750).
} 
Table 2: Comparison of key indicators between survey data and the population from which the sample was drawn

\begin{tabular}{|c|c|c|c|c|c|c|}
\hline & $\begin{array}{c}\text { Kongsvinger } \\
\quad(\mathrm{N}=507)\end{array}$ & $\begin{array}{c}\text { Munici- } \\
\text { pality of } \\
\text { Kongsvinger }\end{array}$ & $\begin{array}{l}\text { Jessheim } \\
(\mathrm{N}=616)\end{array}$ & $\begin{array}{l}\text { Municipality } \\
\text { of Ullensa- } \\
\text { ker (includes } \\
\text { Jessheim) }\end{array}$ & $\begin{array}{l}\text { Drøbak } \\
(\mathrm{N}=843)\end{array}$ & $\begin{array}{c}\text { Municipality } \\
\text { of Frogn } \\
\text { (Includes } \\
\text { Drøbak) }\end{array}$ \\
\hline Average household size & 2.13 & 2.05 & 2.51 & 2.34 & 2.50 & 2.27 \\
\hline $\begin{array}{l}\text { Average number of chil- } \\
\text { dren per household }\end{array}$ & 0.46 & 0.40 & 0.65 & 0.59 & 0.60 & 0.51 \\
\hline $\begin{array}{l}\text { Proportion of children } \\
\text { aged } 0-17\end{array}$ & $22.0 \%$ & $18.9 \%$ & $25.8 \%$ & $24.8 \%$ & $24.2 \%$ & $22.0 \%$ \\
\hline $\begin{array}{l}\text { Average respondent age } \\
(18<=\text { age }<=75 \mathrm{yrs})^{*}\end{array}$ & 52.0 & 47.3 & 48.7 & 43.7 & 52.0 & 47.0 \\
\hline $\begin{array}{l}\text { Gender (Share of } \\
\text { female)* }\end{array}$ & $46.8 \%$ & $51.3 \%$ & $51.0 \%$ & $49.4 \%$ & $53.3 \%$ & $51.4 \%$ \\
\hline $\begin{array}{l}\text { Education level (Share of } \\
\text { college level education) }\end{array}$ & $54.2 \%$ & $21.6 \%$ & $59.2 \%$ & $25.9 \%$ & $66.5 \%$ & $35.0 \%$ \\
\hline Proportion employed & $66.3 \%$ & $56.7 \%$ & $74.5 \%$ & $68.8 \%$ & $72.2 \%$ & $66.8 \%$ \\
\hline $\begin{array}{l}\text { Average household } \\
\text { income (1,000 NOK) }\end{array}$ & 756 & 508 & 854 & 571 & 893 & 583 \\
\hline
\end{tabular}

${ }^{*}$ Gender (Proportion of female) is calculated for the sampling frame, i.e., section of the population $>=18$ years old

\section{$5 \quad$ Analytical model}

The empirical model employed is a multivariate analysis involving multiple linear regression and a logistic regression. First, car driving distance ${ }^{7}$ is regressed linearly on the list of independent variables to investigate the influences of neighborhood, local and regional built environment attributes on car driving distance. Regional influence is modeled by introducing a centrality variable and interacting it with residential location. Second, a binary logistic regression of commuting modes is employed to explore the causal pathways through which residential location influences local and regional car driving distance. The independent variables include built environment attributes (residential distance from the city center, job density and population density), demographics (gender, household size, respondent's age and number of children below 18 years), socioeconomic variables (employment status, education level and income) as well as five residential preference factors (discussed in detail in Section 5.1). An exhaustive list of variables is presented in Appendix 1.

The models are estimated stepwise. To begin with, car driving distance is modeled as a function of a single independent variable, the residential distance from the city center. Additional variable groups of demographic, socioeconomic and other built environment characteristics are then added sequentially into the model. Control variables related to residential preference are also included by the end of the recursive estimation process. At each step, estimates that are significant at a 10\% level are retained. At the final stage of the estimation, only estimates that are significant at $5 \%$ level are reported.

Metric values such as car driving distance and residential distance from the city center are transformed into logarithmic form. Strictly positive values have conditional distributions that often are positively skewed (heteroskedastic). A log transformation mitigates this problem. Log transformation also tends to make ordinary least square regression estimates less sensitive to outlying or extreme values (Wooldridge, 2014).

${ }^{7}$ Car driving distance, as used here, refers to total distance traveled by car with the respondent as a driver. The concept of car refers to automobiles primarily used for personal transport. Ordinary cars, Light pick-up trucks, and other small vehicles used for personal mobility fall in to this category. 
A city's place in a center hierarchy, positions a city in the context of regional socio-cultural and economic life. As such, regional physical attributes are likely to influence individuals' travel decisions. To reflect the effect of regional conditions on car driving distance, two regional variables are defined, namely the centrality variable as well as an interaction term between centrality and residential distance from the city center. The centrality variable, a dichotomous variable, is defined based on whether a city is a satellite or a regional center (see Section 4.1). The centrality dummy assumes the value " 1 " for the regional center and " 0 " otherwise. The rationale for the interaction between the centrality dummy and residential distance from the small-city center, is to test how regional context influences the effect of residential location on driving distance.

\subsection{Factor analysis}

To account for individual heterogeneities due to residential preference, factor variables are extracted from a wide-ranging battery of 4-scale Likert items. In the survey, respondents were asked to indicate the importance of 21 housing and neighborhood characteristics when they were looking for a place to live (or if they were to move to a new dwelling) on a four-point scale from "not at all important" (1) to "highly important" (4).

Likert item-based measures of stated preferences are known to be highly correlated as many of those items measure similar underlying factors. Replacing the preference items with components generated through factor analysis does not only eliminate a potential serial correlation but also compresses the items to the essential underlying factors. Using component factor analysis, the residential preference items are compressed to five factors in two steps. In step one, an exploratory factor analysis on the whole set of 21 preferences generated seven factors. Then, preferences that load on the first five factors were retained using a scree plot. ${ }^{8}$ In step two, the same process was repeated again on the retained preference items ${ }^{9}$ generating the results reported in Table 3.

${ }^{8}$ Due to low loading, four items (low housing cost, proximity to family and friends, architectural quality and familiar neighborhood) were dropped

${ }^{9}$ Further two preference items, namely proximity to train station and proximity to bus stop were dropped in step two due to conceptual interpretability. 
Table 3: Factor analysis of residential preferences and their loading patterns

\begin{tabular}{|c|c|c|c|c|c|}
\hline & Shopping & Family & Amenities & Investment & Exercise \\
\hline Eigenvalue & 2,543 & 1,716 & 1,600 & 1,597 & 1,469 \\
\hline Proximity to other shopping facilities & 0,819 & & & & \\
\hline Proximity to grocery stores & 0,790 & & & & \\
\hline Easy access to shopping mall & 0,750 & & & & \\
\hline Proximity to the city center & 0,718 & & & & \\
\hline Good school/kindergarten & & 0,760 & & & \\
\hline Private garden & & 0,649 & 0,494 & & \\
\hline Proximity to workplace & & 0,594 & & & \\
\hline Good property management & 0,322 & $-0,461$ & & 0,451 & 0,330 \\
\hline Undisturbed location & & & 0,702 & & \\
\hline Nice view & & & 0,613 & & \\
\hline Distance to major road/rail line & & & 0,414 & 0,315 & \\
\hline Favorable investment object & & & & 0,729 & \\
\hline No social problems & & & & 0,716 & \\
\hline Opportunities for physical exercise & & & & & 0,826 \\
\hline Proximity to green areas & & & 0,390 & & 0,735 \\
\hline
\end{tabular}

Notes: 1. Extraction Method: Principal Component Analysis. Variance maximizing rotation (Varimax) was used with Kaiser Normalization. Extraction was based on eigenvalue greater than “1”. Factor loadings smaller than 0.30 were suppressed. 2. Total variance explained is $59.5 \%$

\section{$6 \quad$ Results and discussion}

\subsection{How important is regional hierarchy in influencing car driving distance?}

One of the research questions this paper intended to address is how the regional context influences driving distance and whether the effect of residential location on driving distance varies depending on regional context. To address these questions, a multivariate regression of car driving distance is modeled on built-environment, socio-economic, demographic, residential preference and regional variables. Data from the three small cities are pooled together for this analysis. Table 4 presents model results.

A city's regional context (centrality) has a bearing on car driving distance. Controlling for the other investigated variables, residents of a city that is a regional center (Kongsvinger) drive about $35 \%$ shorter distance than those in the satellite cities (Jessheim and Drøbak) do.

Among the local built environment variables, only residential location is significant. Living far away from the city center is associated with longer car driving distances. Due to the interaction term between centrality and residential location, the net effect of residential location has two components: the independent effect and the interaction effect. The interaction effect, which shows how the effect of residential location varies depending on whether a small city is a satellite or not, is weakly significant. The net effect (sum of the independent effect of residential location and the effect of the interaction term) of residential location is therefore more than twice as high in Kongsvinger as in Jessheim and Drøbak. For Kongsvinger, the effect is in line with the literature (Boarnet, Nesamani, \& Smith, 2003; Ewing \& Cervero, 2010; Næss, 2005; Pushkar, Hollingworth, \& Miller, 2000; Stevens, 2017; Zegras, 2010) whereas it is significantly lower for the satellites. 
Table 4: City-scale and regional effects on car driving distance

\begin{tabular}{lccc}
\hline & Coefficients & Robust std. err. & P-value \\
\hline Log of residential distance from the city center $(\mathrm{km})$ & 0.1051 & .0471 & 0.026 \\
Gender (male) & 0.5355 & .0644 & 0.000 \\
Household income per adult (1000 NOK) & 0.0008 & .0002 & 0.000 \\
Employment & 0.4453 & .0780 & 0.000 \\
Investment factor & 0.0891 & .0329 & 0.007 \\
Centrality & -0.3513 & .0934 & 0.000 \\
Centrality X residential location ${ }^{10}$ & 0.1763 & .0957 & 0.066 \\
Constant & 3.6849 & .0968 & 0.000 \\
R-squared & 0.1387 & & \\
Number of observations & 1356 & & \\
\hline
\end{tabular}

Note: The results are based on pooled data from the three small-cities.

Neighborhood built environment attributes (job density and population density) show no effect on car driving distance. This is as expected and conforms to previous findings (Ewing \& Cervero, 2010; Kockelman, 1997). Among the socio-demographics, gender and employment status exert significant influence, with men driving 54\% longer than women and the employed 45\% longer than those who are not workforce participants. Income is also statistically significant but smaller in effect size, but this is partly because I have also controlled for employment.

\subsection{How significant is regional context and city center structure in the relationship between residential location and car driving distance?}

City center structures and regional context are relevant spatial structures influencing travel decisions. As suggested by the centrality variable and the interaction term between centrality and residential location (Section 6.1), the regional location of a small city has significant implication for the relationship between built environment and car driving distance. To highlight the effect of varying regional context on the relationship between built environment (neighborhood and city-scale variables) and travel behavior, a separate model is developed for each city.

\subsubsection{Kongsvinger city}

Regressing the log of car driving distance on residential distance from the city center and recursively controlling for demographic, socio-economic, neighborhood built environment attributes and residential preferences yields only four significant variables among which residential distance from the city center is the only built environment variable. Table 5 presents summary of the results.

Residential distance from the city center has an elasticity of 0.26 , which is within the mainstream of the literature. Residents who live closer to the city center of Kongsvinger, overall, tend to have fewer total kilometers driven. Built environment attributes at the neighborhood scale, on the other hand, show no influence on car driving distance, which is also in accordance with the mainstream in the literature (Kockelman, 1997; Næss, 2012).

${ }^{10}$ Interaction term between the centrality dummy and the log of residential distance from the city center. 
Among the demographic and socio-economic variables, only gender and employment were found to be influential. The literature conforms widely in that men drive longer distances on average (Hjorthol, 2003, 2008; Zegras, 2010). Similarly, employees, due to their daily commutes, are expected to drive longer distances than those who are not workforce participants. The other two important socioeconomic attributes included in the analysis are income and education. Both are insignificant. ${ }^{11}$ Income remains insignificant when employment and education are not controlled for.

Table 5: Multiple regression analysis of total car driving distance for the city of Kongsvinger

\begin{tabular}{lccc}
\hline & Coefficients & Robust std. err. & P-value \\
\hline Log of residential distance from the city center $(\mathrm{km})$ & 0.2645 & 0.0801 & 0.001 \\
Gender (male) & 0.6622 & 0.1233 & 0.000 \\
Employment & 0.3878 & 0.1232 & 0.002 \\
Investment factor & 0.1277 & 0.0618 & 0.040 \\
Constant & 3.7588 & 0.1271 & 0.000 \\
R-squared & 0.1284 & & \\
Number of observations & 361 & & \\
\hline
\end{tabular}

Note: 1. Dependent variable: Log of car driving distance $(\mathrm{km})$. 2. Job density (number of jobs in a 2 kilometer radius from the residence) is dropped due to high correlation with residential distance from the city center $(\mathrm{r}=0.91)$. Another important reason for its exclusion also relates to micronumerosity. Central urban locations capture the same jobs reducing the variability between observations for that particular variable.

The effect of residential distance from the city center on car driving distance is robust even after controlling for transit commutes (Table 8). This result is an indication that people residing closer to the city center have shorter car driving distance not only because of their tendency to utilize transit but also primarily due to the distance-minimizing effect of the built environment. As a regional center, Kongsvinger employs a substantial proportion of the resident workforce locally, about $72 \%$ for the sample and a comparable 71 per cent for the population in the municipality. This helps reduce regional commuting pattern and overall commuting distances. Lower regional commuting pattern, in turn, is likely to boost the effect of local built environment factors such as residential distance from the city center.

From the residential preference variables, the investment factor is positively associated with driving distance. The result is not counterintuitive as the investment factor may represent consumerism-oriented attitude that might manifest itself as higher levels of driving.

\subsubsection{Drøbak city}

The regression model for Drøbak, besides the built environment variables specified in Section 5, includes residential distance to the second center, AMFI-Drøbak. Model results are presented in Table 6.

\footnotetext{
${ }^{11}$ Theoretically, income may influence travel behavior directly by easing capability constraints and in ways that are more complex such as inducing individuals to adopt a certain lifestyle, which then can have a trickle-down effect on travel behavior. Despite the strong underlying arguments, income has no effect on driving distance at a 5\% significance level even when employment and education are controlled for. Nonetheless, the findings fit well into the narrative of the small city as being secluded from immediate regional influences. The high affluence (average income) among the populace means there is less variability in access to mobility resources.
} 
None of the built environment variables, including residential distance from both centers, have significant influence on car driving distance.

In the literature, residential distance from the city center is established as the built environment variable with strongest influence on car driving distance. The most recent comprehensive reviews put the weighted elasticities of the variable at 0.34 (Stevens, 2017) and 0.22 (Ewing \& Cervero, 2010). The likely explanation for the dissociation in Drøbak of residential distance from both centers and total driving distance is the result of at least two main mechanisms. First, the dispersal of facilities away from the city center weakens the city center as a hub of local travel. Second, regional influence. Drøbak is at the outer edge of the Oslo metropolitan region. As a result, a large proportion of its resident labor force commutes to Oslo. The longer commuting distance hence dwarfs (as a share of total travel distance) whatever gains the local environment may be able to induce in terms of short driving distances and non-motorized travel.

Table 6: Multiple regression analysis of total car driving distance for the city of Drøbak

\begin{tabular}{lccc}
\hline & Coefficients & Robust std. err. & P-value \\
\hline Gender (male) & .6382545 & .0973776 & 0.000 \\
Household income per adult (1000 NOK) & .0008127 & .0002657 & 0.002 \\
Employment & .3693339 & .1221669 & 0.003 \\
Investment factor & .1282386 & .0477896 & 0.007 \\
Family factor & .1095918 & .050912 & 0.032 \\
Constant & 3.726962 & .1464115 & 0.000 \\
R-squared & 0.1394 & & \\
Number of observations & 595 & & \\
\hline
\end{tabular}

Men and the employed have significantly longer total driving distances. Total driving distance for men is $64 \%$ longer than for women. Correspondingly, the employed have $37 \%$ longer driving distance than the unemployed. The effect of gender and employment on car driving distance is as expected and conforms with the literature. Employed individuals tend to travel longer due to daily commutes than those that are not. In addition to gender and employment status, higher levels of income also tend to lead to higher driving distances. Among the residential preference factors, the investment factor and family factor are significant with expected signs.

\subsubsection{Jessheim}

As with the other two cities, multivariate regression with the same model specification and recursive estimation method was repeated for the city of Jessheim. Results are reported in Table 7.

Among the built environment variables, residential distance from the city center has the expected sign and is significantly associated with total car driving distance. Population density also appears to have a positive association with car driving distance, indicating that more densely populated areas initiate higher car driving distance. The sign reversal is an anomaly, nonetheless, opposite to what is widely documented in the literature. One plausible explanation for this could be the non-continuous clusters of residential development around the city of Jessheim. Moreover, individuals often have to drive through the central part of Jessheim to connect to the highway passing through Jessheim. 
Table 7: Multiple regression analysis of total car driving distance for the city of Jessheim

\begin{tabular}{lccc}
\hline & Coefficients & Robust std. err. & P-value \\
\hline Log of residential distance from the city center $(\mathrm{km})$ & 0.1696 & 0.0807 & 0.036 \\
Gender (male) & 0.2972 & 0.1103 & 0.007 \\
Household income per adult (NOK 1000) & .0016 & 0.0003 & 0.000 \\
Employment & 0.4919 & 0.1435 & 0.001 \\
Population density & 0.0013 & .0006 & 0.040 \\
Constant & 3.1544 & .1954 & 0.000 \\
R-squared & 0.1688 & & \\
Number of observations & 437 & & \\
\hline
\end{tabular}

From the socio-economic and demographic characteristics, gender, employment and income are significant with associated semi-elasticities of $0.30,0.49$ and 0.0016 respectively. Controlling for the other investigated variables, men have $30 \%$ longer driving distances than women and the employed $49 \%$ percent longer than the unemployed, while increasing annual gross income by NOK 10000 leads to an increase in driving distance by about $16 \%$. Employment obviously has the highest impact on car driving distance due to the tendency for skilled workers to commute to Oslo similar to what is observed in the city of Drøbak. None of the residential preference indicators is significant in the model for Jessheim.

There are at least three ways by which local-scale built environment attributes can influence total car driving distance. One, by influencing the extent of active travel; two, by influencing the number of local and regional transit commutes; and three, by contributing to shorter trip distances (car driving distance) in the local action space. The following section addresses the likely pathways through which residential distance from the city center influences total driving distance. The relationship between a small-city's built environment and active travel is discussed in detail in another article (Wolday, 2018, under review) and will therefore not be addressed here.

\subsection{How resilient is the effect of local built environment on total driving distance in the face of regional influence?}

The effect of residential distance from the city center on car driving distance is both positive and significant in the cities of Jessheim and Kongsvinger (Tables $5 \& 7$ ). This, however, does not tell whether the relationship characterizes regional influence, influence due to local-scale structural conditions or both. Is the influence of residential location on driving distance due to the local city center being an attractive destination or is it regional pull factors outside the local city's domain that are more influential? To sort out the local from the regional effects, a transit dummy is introduced to the significant estimates in Tables 5,6 and 7. The transit dummy is a dichotomous variable representing commuting by transit three or more days a week. Table 8 summarizes results that are significant at $5 \%$ level.

Commuting by transit three or more days a week turned out to have highly significant effect on car driving distance in all three cities but the effect size is greater in Jessheim and Drøbak. Commuting by transit reduces driving distance on average by the extent of $49 \%, 65 \%$ and $71 \%$ for Kongsvinger, Jessheim and Drøbak, respectively, ceteris paribus.

More importantly, the introduction of the transit dummy causes residential location from the city center to be insignificant in the city of Jessheim. In Kongsvinger on the other hand, the effect of residential location remains unchanged despite controlling for transit commutes. In the case of Drøbak, 
residential location was insignificant prior to controlling for commuting by transit (Table 6).

Looking at the relationship between residential location, regional context and transit commutes, the influence of residential location on car driving distance can be deduced to be indirect. Residential location influences commute mode choice for regional transport with residential distance from the city center acting as proxy for access to transit, more specifically distance to the transit station.

Table 8: The resilience of residential distance from the city center when commuting by transit is accounted for

\begin{tabular}{lcccccc}
\hline & \multicolumn{2}{c}{ Kongsvinger } & \multicolumn{2}{c}{ Jessheim } & \multicolumn{2}{c}{ Drøbak } \\
\hline & Coefficients & P-value & Coefficients & P-value & Coefficients & P-value \\
\hline $\begin{array}{l}\text { Log of residential distance from } \\
\text { the city center (km) }\end{array}$ & 0.2828 & 0.008 & & insig & & insig. \\
Gender (male) & 0.6894 & 0.000 & 0.4160 & 0.000 & 0.5853 & 0.000 \\
Household income per adult & & insig. & 0.0016 & 0.000 & 0.0010 & 0.000 \\
(NOK 1000) & & & & & & Insig. \\
Employment & & Insig. & 0.8793 & 0.001 & & 0.000 \\
Commuting by transit & -0.6643 & 0.000 & -1.0521 & 0.000 & -1.2400 & 0.000 \\
Constant & 3.1977 & 0.000 & 3.2339 & 0.000 & 4.3795 & 0.2901 \\
R-squared & 0.1061 & & 0.2521 & & 469 & \\
Number of observations & 254 & & 347 & & & \\
\hline
\end{tabular}

Note: The commuting by transit variable was added to the significant estimates reported in Tables 5, 6, \& 7 above. In the city of Drøbak, employment is insignificant as a result of controlling for income.

Higher income appears to induce longer driving distances in Jessheim and Drøbak whereas it is insignificant in Kongsvinger. This is likely related to regional influences, that is, higher concentration of specialized jobs in Oslo leading for skilled and well remunerated workers to tend to commute to Oslo. Conversely, less skilled, low-earning workers are likely to take up local jobs, as longer commutes may not be fully compensated. The effect of employment is also stronger in Jessheim and Drøbak mainly due to the longer average commuting distances in both cities.

To back the claim that reduction in car driving distance in Jessheim is due to centrally located commuters choosing to commute by train instead of a car, a logistic regression provides a more direct measure of association between train commute and residential location. Table 9 presents results from a logistic model of commuting by train at least three times a week for commuting distances exceeding 20 kilometers on the usual independent variables specified in the linear regression models above.

Table 9: Likelihood of commuting by train at least 3 days a week among Jessheim respondents

\begin{tabular}{lcccc}
\hline & Coefficient & Robust std. err. & Elasticity & P-value \\
\hline Log of residential distance from the city center & -0.6462 & .2265 & -0.2649 & 0.004 \\
Constant & -0.0352 & .1913 & & 0.852 \\
Nagelkerke $R^{2}$ & 0.051 & & \\
Number of observations & 227 & & & \\
\hline
\end{tabular}

Note: the independent variables in the models include demographics (age, household size, responsibility for transporting children), socio-economic (education, income, employment), built environment (residential distance from the city center, population density, job density) and residential preference factors (shopping, amenities, investment, family and exercise). Summary statistics for the variables related to the model are reported in Table $\mathrm{A} 3$ under the appendix. 
Although the model has lower coefficient of determination (Nagelkerke $\mathrm{R}^{2}$ ), the model as a whole is significant. Only one variable is significant in the model. Residential distance from the city center is negatively and significantly associated with the likelihood of commuting by train. As residential distance from the city center increases from $1 \mathrm{~km}$ to $3 \mathrm{~km}$, the probability of commuting by train declines by 0.17. A further increase in residential location from the city center from $1 \mathrm{~km}$ to $5 \mathrm{~km}$ would correspondingly decrease the probability of commuting by train by 0.24 .

\section{Conclusion}

This article discusses the association between built environment characteristics and car driving distance in a small city context. It started out with the question about whether residential distance from the city center influences car driving distance and whether there is a local or regional dimension to that association.

Survey data from three small cities, namely Kongsvinger, Jessheim and Drøbak, were analyzed. The results underscore that regional context is an important denominator on how and to what extent the influence of the distribution of settlement locations is reflected on travel behavior in a small city context. In a city such as Kongsvinger, where regional pull-factors from a nearby higher-order city is weaker, proximity to the city center significantly reduces total car driving distance. In cities with proximity to a higher-order city, the influence of distance from the city center on driving distance is weaker and likely mediated by transit commutes.

Among the demographic and socio-economic characteristics, gender has a consistently strong influence on car driving distance whereas income and employment are strongest where regional characteristics are influential.

The contribution of any practice-oriented planning research is ultimately measured by how informative it is for the planning practice on the ground. This article tried to shed light on two issues with policy implications: Which policy options are likely to reduce car driving distance originating from small cities? Can densification be a viable guiding principle for urban spatial development in small cities?

Reducing car driving distance originating from a small city may require a combination of policy options geared at the local city-scale travel and regional travel. For local travel, reducing the average distance from the city center would reduce car driving distance. At the regional scale, efficient transit with high average accessibility (with a station at the center of the city) would also reduce car driving distance.

On the issue of densification in small cities, this paper answers the question only partially. The analysis at a local scale shows that proximity to the city center in a monocentrically structured city reduces travel distance by car as well as increases the likelihood of commuting by transit. Hence, densification in and close to the city center can contribute to reducing car driving distance. However, due to the small geographic size, the sustainability potential of small cities lies in fostering travel by active modes. Consequently, the effect of relevant local built environment factors such as accessibility to and dispersal of facilities as well as design features such as street network on active travel have to be explored to give a more nuanced answer.

Small cities are often cash strapped because they lack economies of scale associated with administrative costs while at the same time having a limited taxable population and business base. In such conditions, the push to adopt expansionary spatial development may be more appealing as opposed to densifying at city centers. The question that begs answering is therefore, do small municipalities (cities) have the economic incentive to densify? Future study on the economic viability of densification can help clarify on the incentives to utilize central-city locations for development.

\footnotetext{
${ }^{12}$ Residential distance from the city center is also strongly negatively associated with commuting by transit (bus and train). I chose to run the model with one mode, train commutes, because the train station is located at the city center. Moreover, train is used primarily for regional commutes.
} 


\section{References}

Aguilera, A., \& Mignot, D. (2004). Urban sprawl, polycentrism and commuting. A comparison of seven French urban areas. Urban Public Economics Review, 1, 93-113.

Amundsen, B., \& Lie, E. (2013). Do surveys still give an accurate picture? Fewer willing to participate in surveys. Retrieved from: https://www.forskningsradet.no/en/Newsarticle/Fewer_willing_to_participate_in_surveys/1253986812629

Bhat, C. R., \& Guo, J. Y. (2007). A comprehensive analysis of built environment characteristics on household residential choice and auto ownership levels. Transportation Research Part B: Methodological, 41(5), 506-526. doi:http://dx.doi.org/10.1016/j.trb.2005.12.005

Boarnet, M., \& Crane, R. (2001a). The influence of land use on travel behavior: Specification and estimation strategies. Transportation Research Part A: Policy and Practice, 35(9), 823-845. doi:http:// dx.doi.org/10.1016/S0965-8564(00)00019-7

Boarnet, M., \& Crane, R. (2001b). Travel by design: The influence of urban form on travel. Oxford: Oxford University Press.

Boarnet, M., Nesamani, K., \& Smith, S. (2003). Comparing the influence of land use on nonwork trip generation and vehicle distance traveled: An analysis using travel diary data. Irvine, CA: University of California Irvine, Center for Activity Systems Analysis.

Cao, J., \& Cao, X. (2014). The Impacts of LRT, neighborhood characteristics, and self-selection on auto ownership: Evidence from Minneapolis-St. Paul. Urban Studies, 51(10), 2068-2087. doi: $10.1177 / 0042098013505887$

Cao, X. (2008). Is alternative development undersupplied? Examination of residential preferences and choices of Northern California movers. Transportation Research Record: Journal of the Transportation Research Board, 2077, 97-105. doi:10.3141/2077-13

Cao, X., \& Chatman, D. (2016). How will smart growth land-use policies affect travel? A theoretical discussion on the importance of residential sorting. Environment and Planning B: Planning and Design, 43(1), 58-73. doi:10.1177/0265813515600060

Cao, X., Mokhtarian, P. L., \& Handy, S. L. (2009). Examining the impacts of residential self-selection on travel Behavior: A focus on empirical findings. Transport Reviews, 29(3), 359-395. doi:10.1080/01441640802539195

Cao, X., Næss, P., \& Wolday, F. (2017). Urban containment and inner-city densification reduce auto ownership. Paper presented at the WSTLUR symposium, July 3-6, 2017, Brisbane, Australia.

Cervero, R., \& Kockelman, K. (1997). Travel demand and the 3Ds: Density, diversity, and design. Transportation Research Part D: Transport and Environment, 2(3), 199-219. doi:http://dx.doi. org/10.1016/S1361-9209(97)00009-6

Chatman, D. G. (2009). Residential choice, the built environment, and nonwork travel: Evidence using new data and methods. Environment and Planning A, 41(5), 1072-1089. doi:10.1068/a4114

Chatman, D. G. (2014). Estimating the effect of land use and transportation planning on travel patterns: Three problems in controlling for residential self-selection. Journal of Transport and Land Use, 7(3), 47-56.

Cho, G.-H., \& Rodríguez, D. A. (2014). The influence of residential dissonance on physical activity and walking: Evidence from the Montgomery County, MD, and Twin Cities, MN, areas. Journal of Transport Geography, 41, 259-267. doi:http://dx.doi.org/10.1016/j.jtrangeo.2014.06.007

Christaller, W. (1966). Central places in southern Germany. Englewood Cliffs, NJ: Prentice-Hall.

Circella, G., Mokhtarian, P. L., \& Handy, S. L. (2008). Land use, attitudes, and travel behavior relationships: A cross-sectional structural equations model for Northern California. Paper presented at the 
Transportation Research Board 87th Annual Meeting, Washington, DC.

Crane, R., \& Guo, Z. (2012). Toward a second generation of land-use/travel models: Theoretical and empirical frontiers. In N. Brooks, K. Donaghy, \& G. Knaap (Eds.), The Oxford handbook of urban economics and planning (pp. 522-544). Oxford: Oxford University Press.

Ellegård, K., \& Vilhelmson, B. (2004). Home as a pocket of local order: Everyday activities and the friction of distance. Geografiska Annaler: Series B, Human Geography, 86(4), 281-296. doi:10.1111/ j.0435-3684.2004.00168.x

Ettema, D., \& Nieuwenhuis, R. (2017). Residential self-selection and travel behavior: What are the effects of attitudes, reasons for location choice and the built environment? Journal of Transport Geography, 59, 146-155. doi:10.1016/j.jtrangeo.2017.01.009

Ewing, R., \& Cervero, R. (2010). Travel and the built environment: A meta-analysis. Journal of the American Planning Association, 76(3), 265-294. doi:10.1080/01944361003766766

Ewing, R., Tian, G., Goates, J. P., Zhang, M., Greenwald, M. J., Joyce, A., ... \& Greene, W. (2014). Varying influences of the built environment on household travel in 15 diverse regions of the United States. Urban Studies, 52(13), 2330-2348. doi:10.1177/0042098014560991

Filion, P., Bunting, T., \& Warriner, K. (1999). The entrenchment of urban dispersion: Residential preferences and location patterns in the dispersed city. Urban Studies, 36(8), 1317-1347. doi:10.1080/0042098993015

Fotheringham, A. (1989). Scale-independent spatial analysis. In M. Goodchild \& S. Gopa (Eds.), The accuracy of spatial databases (pp. 221-228). Abingdom, UK: Taylor \& Francis.

Frank, L. D., Saelens, B. E., Powell, K. E., \& Chapman, J. E. (2007). Stepping towards causation: Do built environments or neighborhood and travel preferences explain physical activity, driving, and obesity? Social Science \& Medicine, 65(9), 1898-1914. doi:https://doi.org/10.1016/j.socscimed.2007.05.053

Handy, S., Cao, X., \& Mokhtarian, P. (2005). Correlation or causality between the built environment and travel behavior? Evidence from Northern California. Transportation Research Part D, 10(6), 427-444. doi:10.1016/j.trd.2005.05.002

Handy, S., Cao, X., \& Mokhtarian, P. L. (2006). Self-selection in the relationship between the built environment and walking: Empirical evidence from Northern California. Journal of the American Planning Association, 72(1), 55-74. doi:10.1080/01944360608976724

Hjorthol, R. (2003). Gendered aspects of travel behavior development-are the differences disappearing? Paper presented at the European Transport Conference, October 8-10, Strasbourg, France.

Hjorthol, R. (2008). Daily mobility of men and women-a barometer of gender equality. In T. Cresswell \& T. Uteng (Eds.) Gendered mobilities (pp. 193-210). London: Routledge.

Hjorthol, R., Engebretsen, Ø., \& Uteng, T. P. (2014). The Norwegian Travel Survey 2013/14 - key results. Retrieved from https://www.toi.no/getfile.php?mmfileid=39511

Hong, J., Shen, Q., \& Zhang, L. (2014). How do built-environment factors affect travel behavior? A spatial analysis at different geographic scales. Transportation, 41(3), 419-440. doi:10.1007/s11116013-9462-9

Kendall, M. G., \& Stuart, A. (1961). The advanced theory of statistics (Vol. 2). New York: Charles Griffin Publishers.

Kitamura, R., Mokhtarian, P. L., \& Laidet, L. (1997). A micro-analysis of land use and travel in five neighborhoods in the San Francisco Bay Area. Transportation, 24(2), 125-158. doi:10.1023/a:1017959825565

Kockelman, K. (1997). Travel behavior as function of accessibility, land-use mixing, and land-use balance: Evidence from San Francisco Bay Area. Transportation Research Record: Journal of the Transportation Research Board, 1607, 116-125. doi:10.3141/1607-16 
Kwan, M.-P. (2012). The uncertain geographic context problem. Annals of the Association of American Geographers, 102(5), 958-968. doi:10.1080/00045608.2012.687349

Kwan, M.-P., \& Weber, J. (2008). Scale and accessibility: Implications for the analysis of land use-travel interaction. Applied Geography, 28(2), 110-123. doi:http://dx.doi.org/10.1016/j.apgeog.2007.07.002

Milakis, D., Cervero, R., \& van Wee, B. (2015). Stay local or go regional? Urban form effects on vehicle use at different spatial scales: A theoretical concept and its application to the San Francisco Bay Area. Journal of Transport and Land Use, 8(2), 55-86. doi:10.5198/jtlu.2015.557

Næss, P. (2005). Residential location affects travel behavior-but how and why? The case of Copenhagen metropolitan area. Progress in Planning, 63(2), 167-257. doi:http://dx.doi.org/10.1016/j.progress.2004.07.004

Næss, P. (2006). Urban structure matters: Residential location, car dependence and travel behavior (Vol. 13). London: Routledge.

Næss, P. (2009). Residential self-selection and appropriate control variables in land use: Travel studies. Transport Reviews, 29(3), 293-324. doi:10.1080/01441640802710812

Næss, P. (2011). 'New urbanism' or metropolitan-level centralization? A comparison of the influences of metropolitan-level and neighborhood-level urban form characteristics on travel behavior. Journal of Transport and Land Use, 4(1), 20. doi:10.5198/jtlu.v4i1.170

Næss, P. (2012). Urban form and travel behavior: Experience from a Nordic context. Journal of Transport and Land Use 5(2), 21-45. doi:10.5198/jtlu.v5i2.314

Næss, P. (2013). Residential location, transport rationales and daily-life travel behavior: The case of Hangzhou Metropolitan Area, China. Progress in Planning, 79(0), 1-50. doi:http://dx.doi.org/10.1016/j. progress.2012.05.001

Næss, P. (2014). Tempest in a teapot: The exaggerated problem of transport-related residential selfselection as a source of error in empirical studies. Journal of Transport and Land Use, 7(3), 23. doi:10.5198/jtlu.v7i3.491

Næss, P. (2015). Built environment, causality and travel. Transport Reviews, 35(3),1-17. doi:10.1080/0 1441647.2015.1017751

Næss, P. (2016). Urban planning: Residential location and compensatory behavior in three Scandinavian cities. In T. Santarius, H. J. Walnum, \& C. Aall (Eds.), Rethinking climate and energy policies: New perspectives on the rebound phenomenon (pp. 181-207). Cham, Switzerland: Springer International Publishing.

Næss, P., \& Jensen, O. B. (2004). Urban structure matters, even in a small town. Journal of Environmental Planning and Management, 47(1), 35-57. doi:10.1080/0964056042000189790

Næss, P., Strand, A., Wolday, F., \& Stefansdottir, H. (2017). Residential location, commuting and non-work travel in two urban areas of different size and with different center structures. Progress in Planning. (In press). doi:https://doi.org/10.1016/j.progress.2017.10.002

Norway's Government. (2014). Central government policy guidelines for coordinated land use and transport planning in 1993, amended in 2014. Retrieved from https://www.regjeringen.no/en/dokumenter/National-Policy-Guidelines-for-coordinated-land-use-and-transport-planning/id107851/

Pushkar, A. O., Hollingworth, B. J., \& Miller, E. J. (2000). A multivariate regression model for estimating greenhouse gas emissions from alternative neighborhood designs. Paper presented at the 79th annual meeting of the Transportation Research Board, Washington, DC.

Røe, P. G. (2000). Qualitative research on intra-urban travel: An alternative approach. Journal of Transport Geography, 8(2), 99106. doi:http://dx.doi.org/10.1016/S0966-6923(99)00039-3

Statistics Norway. (2015a). Land use in urban settlements. Area and population of urban settlements, by densely populated area, contents and year. Statistikkbanken, Table: 04859 . Retrieved from http:// 
www.ssb.no

Statistics Norway. (2015b). Register based employment data, 4th quarter, 2015. Retrieved from https:// www.ssb.no/en/arbeid-og-lonn/statistikker/regsys

Stevens, M. R. (2017). Does compact development make people drive less? Journal of the American Planning Association, 83(1), 7-18. doi:10.1080/01944363.2016.1240044

Sun, B., He, Z., Zhang, T., \& Wang, R. (2016). Urban spatial structure and commute duration: An empirical study of China. International Journal of Sustainable Transportation, 10(7), 638-644. doi:1 $0.1080 / 15568318.2015 .1042175$

Wolday, F. (2018). The effect of neighborhood and urban center structures on active travel in small cities. (Under review).

Wolday, F., Cao, J., \& Næss, P. (2018). Examining factors that keep residents with high transit preference away from transit-rich zones and associated behavior outcomes. Journal of Transport Geography, 66(Supplement C), 224-234. doi:https://doi.org/10.1016/j.jtrangeo.2017.12.009

Wooldridge, J. M. (2014). Introduction to econometrics. United Kingdom: Cengage Learning EMEA.

Zegras, C. (2010). The built environment and motor vehicle ownership and use: Evidence from Santiago de Chile. Urban Studies, 47(8), 1793-1817.

Zhang, L., Hong, J. H., Nasri, A., \& Shen, Q. (2012). How built environment affects travel behavior: A comparative analysis of the connections between land use and vehicle miles traveled in US cities. Journal of Transport and Land Use, 5(3), 40-52.

Zhou, B., \& Kockelman, K. (2008). Self-selection in home choice: Use of treatment effects in evaluating relationship between built environment and travel behavior. Transportation Research Record: Journal of the Transportation Research Board, (2077), 54-61. 